\title{
The Use of MOOCs in the Brazilian Classroom: Possibilities for Hybrid Education
}

\author{
Carina Dias da Silva Rodrigues, Andréia dos Santos Sachete, Fábio Diniz Rossi \\ Federal Institute of Education, Science and Technology Farroupilha, Brazil
}

\begin{abstract}
Massive and Open Online Courses - MOOC is a democratic proposal for education and knowledge, given its flexibility characteristics. MOOCs can provide active educational resources, which stimulate the development of learning practically and collaboratively in various areas of expertise. Blended learning can be understood as a mixed teaching regime, characterized by the articulation of traditional on-campus classes and online moments. In this sense, the use of MOOCs in the classroom is a possibility to combine classroom teaching with online teaching, aiming to motivate students in the search for more information and knowledge, making the classes more attractive and productive. of using MOOCs in the classroom. The methodological approach consists of bibliographic research through the literature of studies published in the area.
\end{abstract}

\section{Introduction}

The ease of having a world of content within reach of a click makes the internet today fully inserted into our routines. Although we have a somewhat complicated relationship with this accessibility, the use of the internet as a teaching tool has been growing a lot recently. Several online courses are part of this process, offering free content through virtual learning environments.

Brazilian education has been undergoing constant changes in order to improve students' teaching and learning methodologies. To accompany the transformations of society, the educational process seeks to incorporate technological innovations in the classroom.

The present moment imposes a new context, which is entirely impacted by further Information and Communication Technologies (ICT) [1]. It is necessary to look for new ways and techniques to promote knowledge. In this sense, the use of technologies, such as massive open online courses, can be strategic tools in the educational process.

Technology brings many innovations to various areas of activity, making it easier for institutions and a revolution in processes. In the educational sector, it is no different, MOOC (Massive Open Online Courses) being an excellent option for teaching and promoting a higher education institution. Massive Online Open Courses (MOOCs) are open online courses that are available to anyone with internet access and do not require minimum requirements for those who intend to take them.

MOOCs are open and free courses designed to cater to any interested individual. The high differential of a MOOC is its ability to generate knowledge by students based on connections and content sharing, i.e., its focus is the free learning of expertise by its participants. A MOOC is a democratic proposal for education and knowledge, given its flexibility characteristics. Therefore, an open, online, and the massive course can be used to help the formation of experience.

In this sense, it is necessary to identify studies on the application of MOOCs in the classroom. This article is the result of bibliographical research, therefore descriptive and non-experimental.

It is true that online courses, in general, have been around for some time, but the big difference with MOOCs is that they are offered for free and do not require any face-to-face participation by students.

Everything can be done over the internet, from attending classes to taking exams. Besides, MOOCs have been characterized by the fact that most of the universities that offer them have a solid global reputation, as do the professors involved in developing these courses.

Initially, the concept of MOOCs is exposed. Subsequently, we discuss how MOOCs can be considered a proposal for innovation for teaching and learning. Possibilities for the classroom are presented, such as the use of MOOCs in hybrid education. Finally, the final reflections of this work are presented.

\section{MOOC - Contextualization}

Massive Open Online Courses (MOOC) originated in Canada. Dave Cormier used the term about the model of an Online Course by George Siemens and Stephen Downes. Unlike traditional courses, MOOC serves multiple students at the same time as there is no need to form classes and each student makes their own pace and pace to begin and complete their learning [12][17]. Conole [5] points 
out that one of the main characteristics of these courses is to promote learning through large-scale distributed communities, using open practices.

According to Ma, Lee, and Kuo [8], a MOOC is based on a distance education model, but what distinguishes it from the traditional distance learning is that it is designed to serve a large number of students and, It also allows access to any interested user.

According to Grainger [7] and Yuan and Powell [17], MOOCS can be classified into two strands or models: cMOOC and xMOOC. cMOOCs are based on connectivity, a pedagogical approach that focuses on the generation of knowledge by students, based on connections and content sharing. Already xMOOC has an instructional character, has the figure of the teacher as content transmitter and the priority is not interactivity between learners, but the transmission of content.

Over the years, the teaching and learning process has evolved significantly, awakening new forms of education. In this context of innovations in education, Watters [18] highlights the equalizing capacity of MOOC, as it has the ability to reach several students, regardless of age or social class. Thus, a Mooc is a tool with significant potential to break the paradigms of the classic way of teaching and learning.

Researchers [4] [18] [9] suggest that these Open and Massive Courses are a revolution in teaching and an excellent resource for democratizing education, as it gives any citizen the possibility to access to educational institutions. It is a genuinely innovative mode of learning, a trend in distance education as the ideal for promoting the democratization of free culture, and the open sharing of knowledge.

Also, according to Skiba [13], open courses provide students with dynamic learning, with the possibility of social and collaborative learning "engagement."

MOOCs prove to be a viable alternative for the democratization of knowledge in the process of coauthorship and co-production, providing the flexibility of teaching concerning the time and potentiality of hypermedia educational resources.

\section{MOOC as a proposal for innovation in teaching and learning}

The technological expansion has made educational systems coexist with computers. Andrew $\mathrm{Ng}$ [2] mentions that the internet provides a much more efficient means of transmitting content, and the combination of video classes with live and classroombased classroom emerges as a more effective way to teach students.

Some Brazilian universities offer free courses through the MOOCs methodology, which is a way to provide free access to the knowledge produced by the faculty of the institution through a flexible methodology proposal, which allows students to study wherever they are, anytime and through of the most varied technologies.

There are several possibilities for using MOOCs: they can be applied as support and complement to traditional classes, academic leveling, corporate education, and continuing education and institutional development processes.

One possibility is to use the mass and online courses (virtual modality) in classroom teaching, seeking to relate the knowledge provided in both spaces. For this, it is necessary to offer during the classes, a reflective and interactive space, providing the opportunity for dialogue concerning the learning acquired in both contexts.

MOOCs can provide active educational resources that stimulate the development of learning practically and collaboratively in various areas of knowledge.

The use of these courses in the field of classroom education can bring improvements to teachers and students, favoring the development of significant experiences and learning, considering the current historical, social, and cultural context of digital society.

Indeed, education will increasingly be supported and mediated by technologies; therefore, education professionals need to find alternatives and ways that can take advantage of these opportunities and possibilities that new technologies provide.

In Brazil, the National Education Plan (PNE 2014/2024) defines in its goals that one of the strategies to promote the quality of primary education in all stages and modalities is to stimulate development, assure and disseminate educational technologies for primary education. It encourages innovative pedagogical practices that ensure improved school flow and learning.

Thus, the use of MOOCs meets the goal established in the PNE, as they can be used as a complement to classroom educational activities, to increase research activities, assist mobility and collaboration between teachers and students, and to facilitate access to information.

According to Andrew Ng [2], MOOCs have provided a new orientation in student-teacher relationships, as using online resources frees up teacher time, enabling them to engage with the student actively. It creates a space for discussion, enabling debate and allowing students to learn through handson interaction with teaching materials.

For the author, there is no doubt that the MOOCs bring a different methodological proposal and new behaviors, both teachers and students. Its focus is on interactivity and collaboration on the web, enabling an open Education movement in the effort to make education more accessible and more effective. 


\section{Possibilities in the classroom: hybrid teaching through MOOC}

Hybrid or blended learning [6], one of the trends of 21 st-century education, has been used as a complement to traditional teaching, where online learning is gradually combined with face-to-face teaching without, however, changing the basic teaching model in the classroom [3].

Staker and Horn [14] define blended learning as a formal education program that combines times when students study content and instruction using online resources, and others where teaching takes place in a classroom. Blended learning can be understood as a mixed teaching regime, characterized by the articulation of traditional on-campus classes and online moments.

According to Vaughan [16], the role of hybrid education is to improve and improve student engagement, i.e., what constitutes a better performance. For the author or blended learning is an opportunity to interrogate the curriculum and redesign it as more results, allowing the student to engage with the content in a different way.

Moskal, Dziuban, and Hartman [11], in studies of a mixed learning model at the University of Central Florida, characterize hybrid teaching as a way of connecting old and new in an institution. Blended learning brings together traditional academia and face-to-face teaching, providing opportunities for integrating new technologies and platforms to improve teaching and learning.

The combination of what happens online and what happens in the classroom can be vibrant and benefit students' learning in many dimensions.

In this sense, the use of MOOCs in the classroom is a possibility to combine classroom teaching with online teaching, aiming to motivate students in the search for more information and knowledge, making the classes more attractive and productive.

The intention to complement classroom teaching with distance learning is not recent in Brazil. In 1970, the Minerva Project was implemented, which was intended for adult education and had this peculiarity: on the one hand, the radio transmission, on the other, the in-class moments.

Matheos [10], in his research on Canadian University Hybrid Teaching, mentions the contributions of the method: improved teaching, learning, assessment, retention, performance, and satisfaction of teachers and students.

As mentioned above, MOOC has been used by several institutions of Brazilian higher education respected around the world. This is because it has a social function when making knowledge available for free and also because the institution can use this strategy to capture leads and generate value for its brand. The Brazilian institution needs to demonstrate that it is concerned with the community and is willing to offer knowledge in an accessible manner to anyone interested.

As anyone can have access to the MOOC, it manages to reach a differentiated audience that has no connection with the institution that offers the opportunity. However, when taking a quality course on a given topic, it is common to have an interest in going deeper into the subject. Having already taken the MOOC, the student knows the quality of teaching at the institution that promoted the course and can give preference to it. Therefore, it is interesting to offer classes that are related to other courses available at the educational institution. In this way, it becomes possible to attract new students, who were attracted by some MOOC.

In the same way that the contents can be used by people who have no connection with the Brazilian educational institution, they also offer assistance to those linked to it. This can be done in two main ways, both of which have benefits. First, it can serve as a way to level students in the knowledge needed for a course. When starting graduation, students arrive at very different luggage. In this way, teachers can contribute to the leveling in several subjects, such as basic mathematics, Portuguese, among others. Also, the courses serve as a way to deepen in issues that may have been superficially addressed in undergraduate courses. In this way, a journalism student, for example, can gain more knowledge in photography by doing a specific MOOC on the topic.

\section{Conclusion}

Contemporary education can make use of various digital resources during the teaching and learning process, one of which is the massive open online courses (MOOCs). In this sense, MOOCs are a possibility of access to education, enabling the individual to be included in the education scenario, providing, even in short and short courses, access to some knowledge. These courses notably amplify individuals' access to information, learning, and social and technological inclusion, thereby improving their culture and education.

Teachers can elaborate or suggest the creation of MOOCs, in order to facilitate the expansion and updating of knowledge, considering that they can be used in spaces for reflection and debate, enabling students to share the experiences and knowledge acquired during the course, relating them to the contents worked in class.

The literature on MOOCs is still scarce, and references to classroom applications are developing, mainly when used in primary education. As it is a new theme and yet little tested in our educational system, we believe that the subject has much to be debated, reflected, and studied and will undoubtedly find many difficulties in the Brazilian educational reality. 
Therefore, it can be considered that MOOCs are a didactic-pedagogical possibility for complementation and the formation in the most diverse areas of the knowledge and the different levels of education, which are capable of provoking changes in the profile and the teaching work, as well as in the management of educational institutions. Therefore, it is clear that MOOCs are an innovation for teaching, as they encourage educational institutions to rethink the process of curriculum design for more open and flexible educational models.

In this way, MOOCs are efficient and accessible teaching models for Brazilian institutions, which have made it possible for people of different ages, regions and needs to be able to increase their knowledge baggage thanks to technological advances. Companies and educational institutions can take advantage of this modality to complement their learning processes, reinforcing content, and including additional materials for students.

Thus, it is possible to provide quality content in the education of students and employees, without making significant financial, logistical and strategic investments: find the most suitable course for your purpose and have a device with internet access. Also, massive open online courses bring other advantages of new technologies, such as providing student autonomy, flexible teaching, and engaging participants when mainly using technology.

However, it is necessary to understand that it is not enough to offer MOOCs to have active learning in the educational institution. Other strategies can and should be adopted to complement traditional education and bring even more results. One of the innovative methodologies that have been calling attention is gamification [15]. This strategy combines elements of games with the performance of actions with real impacts, such as studying and doing the fixation exercises. The participants are motivated by the playful resources to complete the activities and to engage in the dynamics, thus having better learning results.

Gamification can be used both by educational institutions and companies, creating an immersive and interactive teaching experience. By adopting electronic platforms, it is possible to access detailed reports of the participants' performance, bringing data to improve their learning further.

\section{References}

[1] Anderson, T., McGreal, R., Disruptive Pedagogies and Technologies in Universities. Educational Technology and Society, v.15, n.4, p. 380-389, 2012.

[2] Ng, Andrew. Learn without limits by improving access to education with MOOCs. Journal of the Brazilian $\begin{array}{llll}\text { Computer } & \text { Society. } & 22 . & 02 / 2013\end{array}$
http://www.sbc.org.br/jdownloads/CB2013/computacao22 jul_2013.pdf.

[3] Bates, Tony. (2015). Teaching in a Digital Age: Guidelines for Designing Teaching and Learning. Vancouver BC: Tony Bates Associates Ltd. ISBN: 978-09952692-0-0.

[4] Carey, K. Into the Future With MOOC's. (massive open online courses), (Essay), The Chronicle of Higher Education, Sept, 2012, Vol.59 (02), Cengage Learning, Inc.

[5] Conole, G. G. (2015). MOOCs as Disruptive Technologies: Strategies for Enhancing the Learner Experience and Quality of MOOCs. Revista de Educación a Distancia, No. 39.

[6] Hinkelman, D. (2018). Blended Learning. In The TESOL Encyclopedia of English Language Teaching (eds J.I. Liontas, T. International Association and M. DelliCarpini).

[7] Grainger, B. Introduction to MOOCs: avalanche, illusion or augmentation. Policy Brief- UNESCO (july). Institute for Information Technologies in Education. 2013. Disponível em: http://iite.unesco.org/pics/publications/en/ files/3214722.pdf. Acesso em 20 de novembro 2019.

[8] Ma JD, Lee KC., e Kuo GM., A massive open online course on pharmacogenomics: not just disruptive innovation but a possible solution. Pharmacogenomics. 2013 Jul;14(10):1125-7. doi: 10.2217/pgs.13.97

[9] Martin, F. G., Education: will massive open online courses change how we teach? Communications of the ACM , 2012 vol:55 iss:8 pg:26 -28.

[10] Matheos, K.: Cleveland-Innes, M.; Blended Learning: enabling Higher Education Reform. Electronic Journal of Education, v. 12, no. 1, p. 238-244, Jan./abr. 2018. http://www.reveduc.ufscar.br/index.php/reveduc/article/vie $\mathrm{w} / 2524 / 681$

[11] Moskal, P.; Dziuban, C.; Hartman, J. Blended learning: A dangerous idea? The Internet and Higher Education, 18, 15-23, 2013. http://dx.doi.org/10.1016/j.iheduc.2012. 12.001 .

[12] Smith, L., 5 Education Providers Offering MOOCs Now or in The Future. EducationDIVE, 2012. http://www.educationdive.com/news/5-moocproviders/ 44506.

[13] Skiba, D. J., Disruption in Higher Education: Massively Open Online Courses (MOOCs). Nursing Education Perspectives, v. 33, n. 6, p. 416-417, 2012.

[14] Staker, H.; Horn, M. B. Classifying K-12 blended learning. Mountain View, CA: Innosight Institute, Inc. 2012. https://www.christenseninstitute.org/wp-content/ uploads/2013/04/Classifying-K-12-blended-learning.pdf.

[15] Harman, K., Koohang, A. and Paliszkiewicz, J. (2014). Scholarly interest in gamification: a citation network 
analysis, Industrial Management \& Data Systems, Vol. 114 No. 9, pp. 1438-1452.

[16] Vaughan, N. D.; Cleveland-Innes, M.; Garrison, D. R. Teaching in blended learning environments: Creating and sustaining communities of inquiry. Athabasca University Press, 2013.

[17] Yuan, L.; Powell, S. MOOCs and Open Education: Implications for Higher Education. Bolton, UK: CETIS/University of Bolton, 2013. http://publications.cetis.ac.uk/2013/667.

[18] Watters, A. MOOC Mania: Debunking the hype around massive open online courses. School Library Journal. April 2013. https://www.slj.com/?detailStory=got-moocmassive-open-online-courses-are-poised-to-change-theface-of-education. 